\title{
Congress probes NIH stimulus funds
}

\author{
Scrutiny also aimed at National Children's Study.
}

Hard on the heels of their \$10.4-billion gift to the US National Institutes of Health (NIH), members of Congress have made it clear that they will keep close tabs on how the biomedical agency spends the money.

At a 26 March hearing of the House subcommittee that funds the $\$ 30.3$-billion agency, Democrats and Republicans grilled top NIH officials on how - and by how much - it will boost the economy with the $\$ 10.4$ billion supplied in February's economic stimulus package (see Nature 457, 942-945; 2009). "With that kind of increase, the committee will be watching carefully to be sure that the NIH spends it in a way that both stimulates the science [and creates] high paying jobs across the country," said Jesse Jackson Jr (Democrat, Illinois), who chaired the hearing.

Jackson said he was concerned that the abrupt curtailment of the bolus of funds, on 30 September 2010, could leave many scientists stranded in a much more difficult funding environment. "The Recovery Act funding is a double-edged sword," he said. "The prosperity is short-lived."

Raynard Kington, acting NIH director, told the subcommittee that the agency aims to avoid repeating the "not so soft" landing that occurred after its budget doubled between 1998 and 2003, then plateaued. The short-term projects slated for the NIH's stimulus money (see 'Spending power') include a new category announced last week: 'grand opportunities' grants, aimed at large-scale projects costing more than $\$ 500,000$ per year. The NIH intends to fund these at about $\$ 200$ million in total.

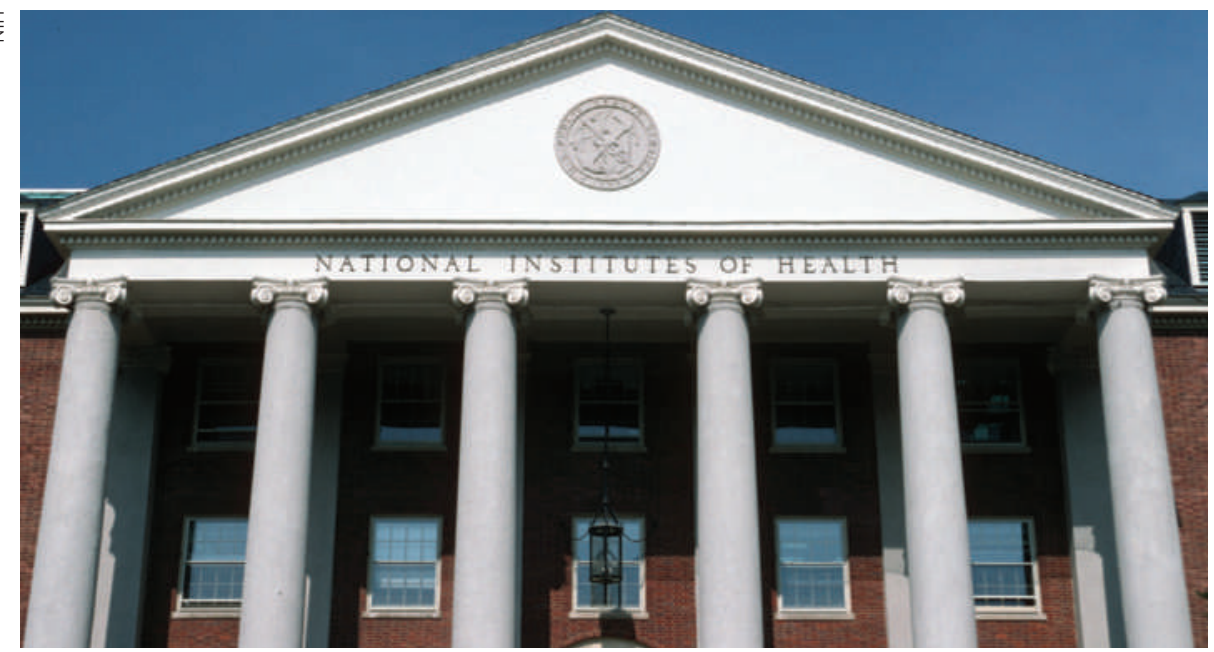

The NIH must detail the economic benefits and number of new jobs it will create with stimulus monies.

\section{SPENDING POWER}

The $\mathrm{NIH}$ received $\$ 10.4$ billion in the US economic stimulus package. $\$ 7.4$ billion of that will be used by individual institutes, much of it on grants already in the applications pipeline. The new pot of money many scientists are scrambling for is the $\$ 800$ million granted to the director's office. Of this, roughly $\$ 291$ million has been committed:

- At least $\$ 200$ million to Challenge Grants

- Roughly $\$ 91$ million to programmes including Signature Initiatives, Core Centers for Enhancing Research Capacity in US Academic Institutions, and summer training programmes

The remaining roughly $\$ 509$ million will be committed later by the director, partly in Grand Opportunity Program grants.

However, Kington concedes, the agency may see a rise in grant applications beginning in 2011 if the stimulus money works as hoped to foster new discoveries and accelerate research. If that happens, he says, "we believe the success rate may drop at least several points from what it has been if we don't have a substantial increase in our budget".

Republicans on the subcommittee seemed sceptical that the stimulus funding would be spent on the best science. "Give us some confidence that, one, this will stimulate the economy as intended and, two, that you are not just going to be throwing money at new projects that hadn't made the [fundable] list before," said Dennis Rehberg (Republican, Montana). The agency is revisiting 14,000 grant applications already in the NIH's pipeline that were judged to be scientifically meritorious but that were not funded in its last round of reviews. These may now receive funding if they can show potential to make progress within two years.

Kington defended those applications, calling the projects at "the top, right below our funding level". As for job creation, he says, the biomedical agency has estimated that each of its grants supports on average "six or seven jobs in part or in full". Pressed further by Rehberg, Kington said he would get back to him with the exact number of jobs to be created with the NIH's $\$ 10.4$ billion. Few expect this to be an easy number to find (see page 563).

Also under fire at the same hearing was the National Children's Study, a project first authorized by Congress in 2000 that aims to follow environmental and genetic influences on the health of 105,000 children from the womb to the age of 21. During its planning phase, the Bush administration repeatedly tried to kill its funding, and Congress repeatedly restored it. This year, it is receiving $\$ 192$ million - up from $\$ 111$ million in 2008. Its seven 'vanguard' centres, conducting its pilot phase, will all be open and beginning to enrol patients this month.

But shifting numbers on its estimated cost have become a political pitfall. Several months ago, NIH officials called Todd Tiahrt, the subcommittee's senior Republican, to explain that the initial \$3-billion-plus price tag on the study could end up being double that amount. Last week, Kington told Tiahrt that the agency had been estimating "a moving target" while the study was in the planning stages, and that when it became apparent that the study would cost more than originally expected, the NIH decided not to adjust the estimate upwards until the results of the pilot study were in. "That was an error in judgement," Kington says. "We have every plan to bring the cost down."

After the hearing, Duane Alexander, the director of the National Institute of Child Health and Human Development in Bethesda, Maryland, called the contention that the project's costs had doubled "a myth". During the pilot phase of the study, he says, "we have an attractive tree to hang ornaments on", referring to the lengthy list of subprojects encompassed by the pilot. "There was never any expectation or intent that we would be able to fund all that."

See also Party of One, page 563. 